GU J Sci, Part C, 6(3): 668-679 (2018)

Gazi Üniversitesi
Fen Bilimleri Dergisi
PART C: TASARIM VE TEKNOLOJI
dergipark.gov.tr/http-gujsc-gazi-edu-tr

\title{
Östemperlenmiş Küresel Grafitli Dökme Demirlerde İndüksiyonla Yüzey Sertleştirmenin Yorulma Sınırı Üzerine Etkisi
}

\author{
Erkun OKTAY ${ }^{1}$, Volkan KILIÇLI ${ }^{2 *}$, Mehmet ERDOĞAN ${ }^{2}$ \\ ${ }^{I}$ Gazi Üniversitesi, Fen Bilimleri Enstitüsü, Metalurji ve Malzeme Mühendisliği Bölümü, 06560, Teknikokullar/ANKARA \\ ${ }^{2}$ Gazi Üniversitesi, Teknoloji Fakültesi, Metalurji ve Malzeme Mühendisliği Bölümü, 06560, Teknikokullar/ANKARA
}

\begin{abstract}
$\ddot{O} \mathbf{z}$
Makale Bilgisi

Başvuru: 09/03/2018 Düzeltme: 10/05/2018

Kabul: 29/05/2018

Anahtar Kelimeler

$\mathrm{Bu}$ çalışmada, östemperlenmiş küresel grafitli dökme demirlerde indüksiyonla yüzey sertleştirmenin yorulma sınırı üzerine etkisi araştırılmıştır. Bu amaçla, GGG70 sınıfı küresel grafitli dökme demir numuneler; $900^{\circ} \mathrm{C}$ ' de $90 \mathrm{dk}$ östenitlenmiş ve ardından $375^{\circ} \mathrm{C}$ sıcaklıktaki tuz banyosunda $120 \mathrm{dk}$ östemperlenmiştir. Daha sonra dökülmüş ve östemperlenmiş koşullardaki yorulma numunelerine yüksek frekanslı indüksiyonla yüzey sertleștirme uygulanmıştır. Dökülmüş halde, östemperlenmiş, dökülmüş halde + indüksiyonla sertleştirilmiş ve östemperlenmiş̧indüksiyon ile sertleştirilmiş numunelerin yorulma sınırları, dönel eğmeli yorulma testi cihazı belirlenmiştir. Deneysel sonuçlar, test edilen numuneler arasında en iyi yorulma sınırı sonuçlarını östemperlenmiş+yüzeyi indüksiyonla sertleştirilmiş numunelerin sergilediğini göstermiştir.
\end{abstract}

Küresel grafitli dökme demir

Östemperlenmiş küresel

grafitli dökme demir

(ÖKGDD)

İndüksiyonla yüzey

sertleștirme,

Yorulma Sinirl

Keywords

Ductile Iron

Austempered Ductile Iron

(ADI)

Induction Surface

Hardening

Fatigue limit

\section{Effect of Induction Surface Hardening on Fatigue Limit of Austempered Ductile Irons}

\begin{abstract}
In this study, the effect of induction surface hardening on the fatigue limit of austempered ductile iron was investigated. For this purpose, samples of grade GGG70 ductile iron were austenitized at $900^{\circ} \mathrm{C}$ for 90 minutes and then austempered in a salt bath at $375^{\circ} \mathrm{C}$ for 120 minutes. Then, surface hardening was performed to the fatigue samples in cast and austempered conditions with high frequency induction. The fatigue strengths of the as cast, austempered, as cast+induction surface hardened and austempered+induction surface hardened specimens were determined by the rotational bending fatigue method. Experimental results show that austempered + surface induction hardened specimens exhibited the best fatigue strength results among the tested samples.
\end{abstract}

\section{GİRIŞ (1. INTRODUCTION)}

Küresel grafitli dökme demirler (KGDD) diğer dökme demir türleri ile karşılaştırıldığında mekanik özelliklerinin en iyi konumda olması, çelik malzemelere göre ucuz oluşu, seri üretime uygunluğu artık önemli bir yapı malzemesi olarak dikkat çekmektedir [1].

Östemperlenmiş küresel grafitli dökme demirler (ÖKGDD), KGDD’lere uygulanan östemperleme operasyonuyla üretilmektedir. ÖKGDD'ler esasen düşük karbonlu ferrit ve yüksek karbonlu östenit içeren mikroyapıya sahiptirler. ÖKGDD'ler, mükemmel bir dayanım, süneklik, tokluk ve yorulma direncinin kombinasyonu sergilemektedirler [2-10]. Bu nedenle otomotiv sektöründeki önemli parçalardan olan krank ve kam milleri ve dişliler gibi parçaların üretimlerinde giderek yaygınlaşan şekilde kullanılmaya başlanmıştır $[11,12]$. Bu parçalar kullanım sırasında sürtünerek çalışmaları söz konusu olduğu için sürtünen yüzeylerde aşınma direnci ön plana çıkmaktadır. Yine bu parçalar kullanım sırasında tekrarlı gerilmelere maruz kaldıkları için yorulma sınırlarının iyileştirilmesi de büyük önem arz etmektedir. 
Günümüzde çelik ve dökme demir malzemelerinin yüzey mikro yapısının kimyasını değiştirmeden yüzeylerinin sertleştirilmesinde indüksiyonla yüzey sertleştirme metodu yaygın olarak kullanılmaktadır. Bu metotla yüzeyde elde edilmek istenen sert katman derinliği hassas bir şekilde kontrol edilebilmektedir. Diğer bir avantajı da sertleştirilmek istenen yüzey bölgesinin sıcaklığını östenitleme sıcaklığına çok kısa bir sürede (yaklaşık 3-5 sn) çıkarabilmesidir. Bu işlemin ardından yapılan hızlı soğutma işlemi ile sıcaklığın öze doğru yayılması önlenebildiğinden özdeki yapının dönüşüme uğraması engellenirken yüzeyde martensitten oluşan aşınmaya dirençli sert bir yapı oluşturulabilmektedir. Yüzeyde oluşturulan bu yapının aşınma direncini iyileştirmenin yanında yüzeyde oluşan basma kalıntı gerilmelerinde dolayı yorulma sınırına pozitif katkıda bulunmasıdır [13-19].

Metalik malzemelerde yüzeyde oluşturulan basma kalıntı gerilmeleri yorulma sınırını iyileştirmektedir. Östenitten martensite dönüşüm hacimce büyümeyi gerektirdiğinden yüzey sertleştirme sırasında yüzeyde basma kalıntı gerilmeleri oluşmaktadır. Bu durumda yorulma sınırında da iyileşme beklenebilir.

Literatürde KGDD ve indüksiyonla yüzey sertleştirmenin yorulma sınırı üzerine etkisi ile ilgili çok sınırlı sayıda çalışmaya rastlanmışırı [13-19]. Literatürde ÖKGDD'lere lazer ve elektron ışın metodu yüzey sertleştirme çalışmalarına [20-25] rastlanmakla beraber, ÖKGDD'lere indüksiyonla sertleştirme çalışmalarına rastlanmamıştır. Bu çalışmanın amacı, ÖKGDD'lerde indüksiyonla yüzey sertleştirmenin yorulma sınırına etkisi incelemek olmuştur.

\section{DENEYSEL ÇALIŞMALAR (2. EXPERIMENTAL STUDIES)}

Ergitme işleminde $350 \mathrm{~kg}$ kapasiteli orta frekanslı ergitme tipi indüksiyon ocağı kullanılmıştır. Küreselleştirme ve aşılama işlemleri döküm sıcaklığına $\left(\sim 1490^{\circ} \mathrm{C}\right)$ ulaştıktan sonra yapılmıştır. Küreselleştirme işlemi Tundish tipi işlem potasında, aşılama işlemi döküm potasında gerçekleştirilmiştir. İşlem potasına alınan sıvı metalin döküm işlemleri yaş kum kalıplara yapılmıştır. Kum kalıp tasarımı TS526'da belirtilen Y bloklardan Y-II tipine göre hazırlanmıştır. Elde edilen dökme demirin kimyasal bileşimi Tablo 1'de verilmiştir.

Tablo 1. Dökülmüş koşullardaki küresel grafitli dökme demirin kimyasal bileşimi (Ağırlıkça-\%) (Table 1. The chemical composition of as-cast ductile iron (weight-\%))

\begin{tabular}{|c|c|c|c|c|c|c|c|c|}
\hline$C$ & $S i$ & $M n$ & $P$ & $S$ & $M g$ & $C r$ & $N i$ & $M o$ \\
\hline 3,80 & 2,60 & 0,30 & 0,035 & 0,012 & 0,045 & 0,02 & 0,02 & $<0,001$ \\
\hline$C u$ & $A l$ & $T i$ & $V$ & $N b$ & $W$ & $C o$ & $S n$ & $F e$ \\
\hline 0,065 & 0,005 & 0,01 & 0,004 & $<0,001$ & $<0,005$ & 0,003 & 0,002 & Kalan \\
\hline
\end{tabular}

Y bloklardan işlenen numuneler $900^{\circ} \mathrm{C}^{\prime}$ de 90 dakika östenitlemenin ardından $375^{\circ} \mathrm{C}$ 'deki $\% 50 \mathrm{KNO}_{3}+$ \% $50 \mathrm{NaNO}_{3}$ karışımından oluşan tuz banyosuna aktarılmış ve bu sıcaklıkta 120 dakika östemperlenmiş ve daha sonra durgun havada oda sıcaklığına soğutulmuştur.

Daha sonra dökülmüş ve östemperlenmiş şartlardaki numunelerin yüzeylerine yüksek frekanslı indüksiyonla yaklaşık $950^{\circ} \mathrm{C}$ 'de östenitleme ve ardından yağda su verme işlemleri uygulanmıştır. $\mathrm{Bu}$ işlemlerle yüzeyden yaklaşı $1 \mathrm{~mm}$ derinliğe kadar martensitik yapı oluşturulmuştur.

Isıl işlem uygulanan $12 \times 12 \times 4 \mathrm{~mm}$ boyutlarındaki numuneler standart metalografik yöntemlerle (Zımparalama + Polisaj) metalografik inceleme için hazırlanmıştır. Isıl işlem sırasında numune yüzeyinde oluşabilecek dekarbürize bölgesinin metalografik ölçüm sonuçlarını etkilememesi için yüzeyden az 0,5 mm'lik derinliğe kadar olan kısım yüzeyden taşlanarak uzaklaştırılmıştır.

Dağlayıcı olarak \% 2 Nital çözeltisi kullanılmıştır. Mikroyapıların görüntülenmesinde Leica DFC320 dijital kamera bağlantılı Leica DM4000M marka optik mikroskopta gerçekleştirilmiştir. Ösferrit ve perlit hacim oranı görüntü analiz programı (Leica Q550 MW) kullanılarak hesaplanmıştır. Numunelerin faz hacim oranı ölçümleri 100 büyütmede 10 ayrı bölgeden çekilen mikroyapı fotoğrafları üzerinden yapılarak ortalama değerler alınmıştır. Kırık yüzey incelemelerinde Jeol JSM 6060LV taramalı elektron mikroskobu (SEM) kullanılmıştır. 
Numunelerin yüzey sertliklerinin ölçümünde Instron-Wolpert marka Diatestor 7551 model sertlik ölçüm cihazı 30 kgf yük kullanılarak Vickers sertlik yöntemiyle belirlenmiştir. En az 10 farklı bölgeden alınan sertlik değerlerini ortalaması alınarak yüzey sertlik değeri belirlenmiştir. İndüksiyonla yüzeyi sertleştirilmiş numunelerin sertlik profilleri Emco DuraScan 30 model mikrosertlik ölçüm cihazı $1 \mathrm{kgf}$ yük kullanılarak Mikrovickers sertlik yöntemiyle belirlenmiştir. Mikrosertlik ölçümleri yüzeyden öze doğru 0,2 mm aralıklarla ölçümler alınarak sertlik profilleri elde edilmiştir. Etkin sertlik derinliği (Rht) sertlik profil eğrisinde yüzey sertlik değerinin \%80 değerine karş1lık gelen sertlik derinliği hesaplanarak bulunmuştur.

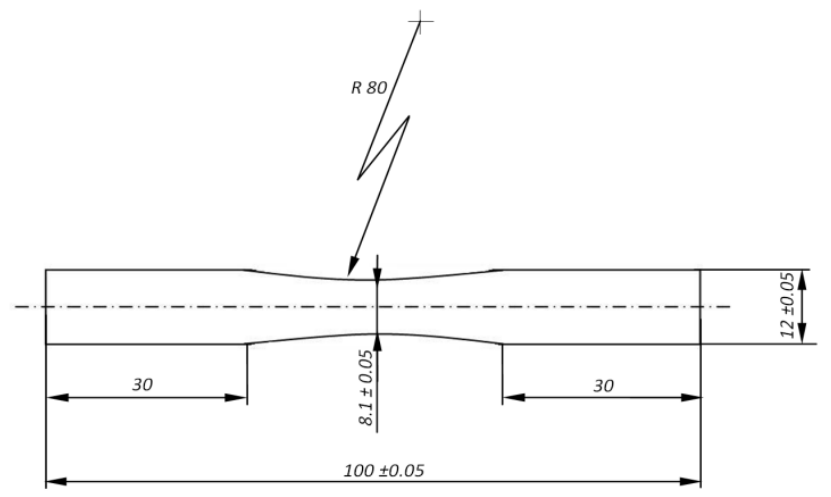

Şekil 1. ISO 1143 standardına göre hazırlanmış silindirik yorulma nunumesinin ölçüleri (Figure 1 . Dimensions of the cylindirical fatigue samples prepared according to ISO 1143)

Yorulma deney numuneleri, dökülen Y bloklardan ISO 1143 standardına göre torna ile işlenmiştir (Şekil 1). Yorulma numunelerinde yorulma test sonuçlarını etkileyebilecek işleme sırasında yüzeyde oluşan izlerin çentik etkisini elimine etmek için yüzeyden $0.5 \mathrm{~mm}$ derinliğe kadar olan kısım taşlanarak yüzey pürüzlülügü en aza indirilmiştir. Yine bu numuneler dikey eksende sırasıyla 220, 400, 800 ve 1200 grit zımpara ile zımparalanmış ve daha sonra $6 \mu \mathrm{m}$ ve $3 \mu \mathrm{m}$ elmas pasta süspansiyonu ile parlatılarak yorulma deneyleri için hazır hale getirilmiştir. Yorulma deneylerinde dönel-eğmeli (Wöhler tipi) yorulma test cihazı kullanılmıştır (Şekil 2).

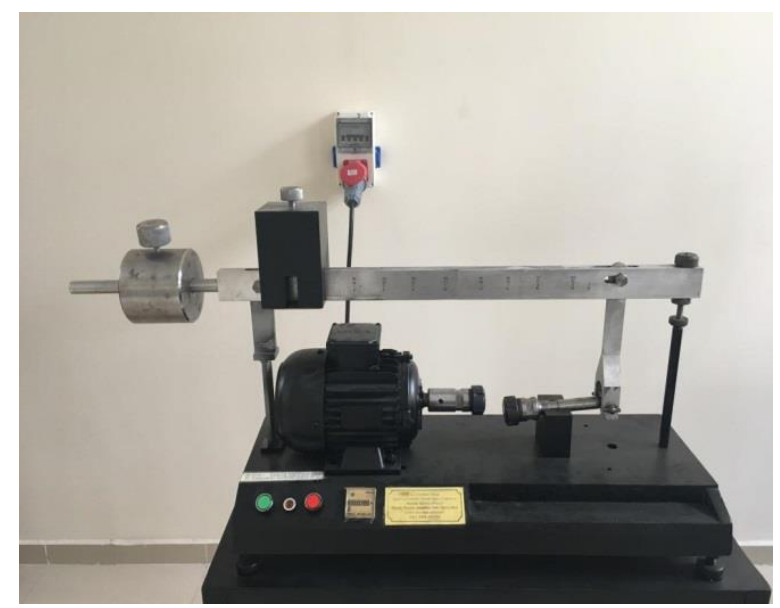

Şekil 2. Deneylerde kullanılan dönel-eğmeli yorulma test cihazı (Figure 2. Rotary-bending fatigue test machine used in the experimental studies) 


\section{DENEYSEL SONUÇLAR VE DEĞERLENDIRME (3. EXPERIMENTAL RESULTS AND EVALUATION)}

\subsection{Mikroyapısal İnceleme (3.1. Microstructural Examination)}

Dökülmüş koşullardaki küresel grafitli dökme demir (KGDD) ve östemperlenmiş koşullardaki küresel grafitli dökme demir (ÖKGDD) numunelerin optik mikroyapı görüntüleri Şekil 3 'te verilmiştir. KGDD mikroyapıs1 perlit+grafit + ferritten oluşmuştur (Şekil 3.a). Grafitlerin etrafinda gözlenen ferritin oluşturduğu beyaz halkalar tipik dana gözü adı verilen yapıyı yansıtmaktadır.

ÖKGDD malzemenin mikroyapısının ösferitten [(ferrit $(\alpha)+$ yüksek karbonlu östenitten $\left.\left(\gamma_{\mathrm{yk}}\right)\right]$ oluştuğu belirlenmiştir. Mikroyapıda koyu faz ferrit $(\alpha)$ ve açık renkli faz yüksek karbonlu östeniti $\left(\gamma_{\mathrm{yk}}\right)$ göstermektedir (Şekil 3.b).
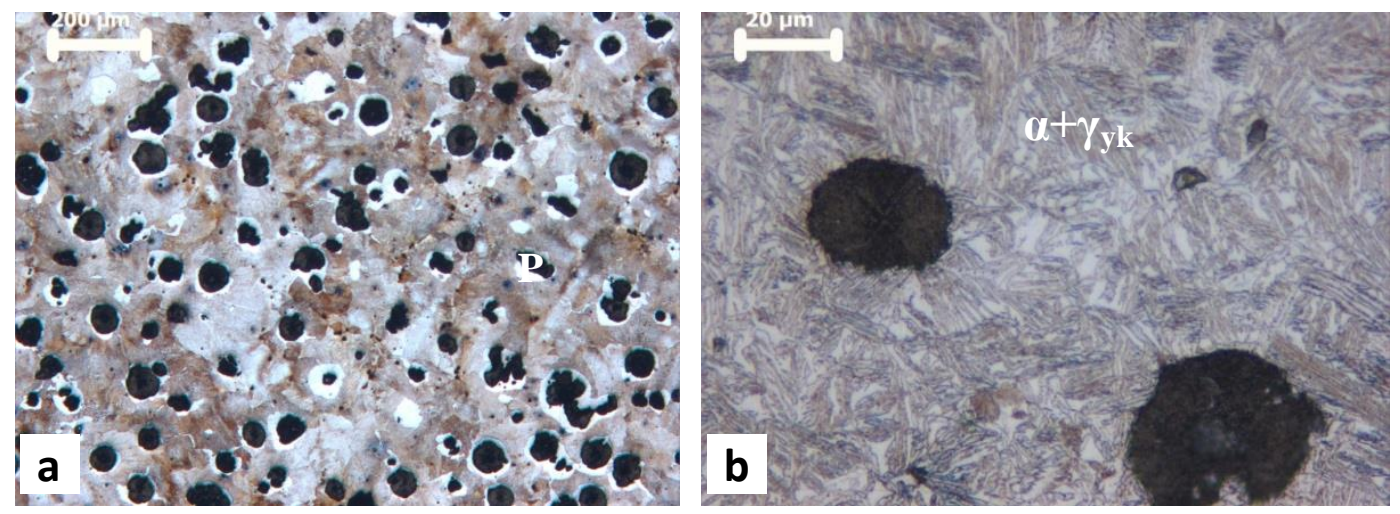

Şekil 3. a) Dökülmüş haldeki KGDD’nin mikroyapısı, b) Östemperlenmiş KGDD’in mikroyapısı, P: Perlit, $\alpha+\gamma_{h c}$ : Ösferrit, Dağlama: \% 2 Nital. (Figure 3. a) Microstructure of as-cast ductile iron, b) Microstructure of austempered ductile iron, P: Pearlite, $\alpha+\gamma_{h c}$ : Ausferrit, Etchant: 2\% Nital)

Dökülmüş ve östemperlenmiş koşullardaki malzemenin metalografik ölçüm sonuçları Tablo 2'de verilmiştir. Dökümüş koşullarda KGDD'in nodularitesinin oldukça iyi olduğu ve grafit hacim oranının ticari KGDD'ler ile uyumlu olduğu belirlenmiştir.

Tablo 2. Dökülmüş ve östemperlenmiş koşullardaki küresel grafitli dökme demirin nicel metalografi sonuçlar (Table 2. Quantitative metallography results of ductile irons in as-cast and austempered conditions)

\begin{tabular}{|c|c|c|c|c|}
\hline Koşullar & $\begin{array}{c}\text { Küreselleşme } \\
\text { Derecesi } \\
\text { (Nodularite) } \\
(\boldsymbol{\%})\end{array}$ & $\begin{array}{c}\text { Grafit } \\
\text { Hacim } \\
\text { Oranı } \\
\mathbf{( \% )}\end{array}$ & $\begin{array}{c}\text { Ösferrit } \\
\text { Hacim Oranı }\end{array}$ & $\begin{array}{c}\text { Ferrit } \\
\text { Hacim } \\
\text { Oranı } \\
(\boldsymbol{\%})\end{array}$ \\
\hline Dökülmüş halde & 92 & 11,5 & $81 *$ & 7,5 \\
\hline Östemperlenmiş & 92 & 11,5 & 88,5 & - \\
\hline *Perlit Hacim Oranı
\end{tabular}

İndüksiyonla yüzeyleri sertleştirilen IYYS+KGDD ve IYS+ÖKGDD numunelerinin optik mikroyap1 görüntüleri Şekil 3'te verilmiştir. IYYS+KGDD numunelerinde yüzeyden 1,26 mm'lik derinliğe kadar martensitik yapı oluşurken özdeki dökülmüş haldeki perlit+ferritten oluşan mikroyapı varlığını korumuştur (Şekil 4.a). Yüzeyden öze doğru inildikçe martensitik bölgeden dökülmüş haldeki mikroyapıya geçiş görülmektedir. İndüksiyonla yüzey ssıtma sonucu yüzey bölgesinin östenit yapıya dönüştürülmesi ve ardından hızla su verme işlemleri çok kısa sürede (yaklaşık $5 \mathrm{sn}$ ) gerçekleştirildiği için ancak yüzeyde oluşturulan östenitik yapının martensite dönüşümü mümkün olabilmektedir. Özdeki yap1 hızlı 1sıtma ve soğutma sonucu dönüşüme uğramadığı için varllğgını sürdürebilmektedir. Yüzey sertleştirme işlemlerinde istenen özellik yüzeyde sert bir yapı (martensitik) oluş̧turulurken özde tokluğu yüksek daha sünek bir yapının varlığını koruyabilmesidir. İYS bu özellikleri karşılayabilir niteliktedir. 
Ayrıca yüzeyde oluşturulan martensitik yapının oluşturduğu basma kalıntı gerilmeleri yorulma özelliklerini pozitif yönde etkilemektedir. Bu etki mekanik özellikler kısmında tekrar değerlendirilecektir.
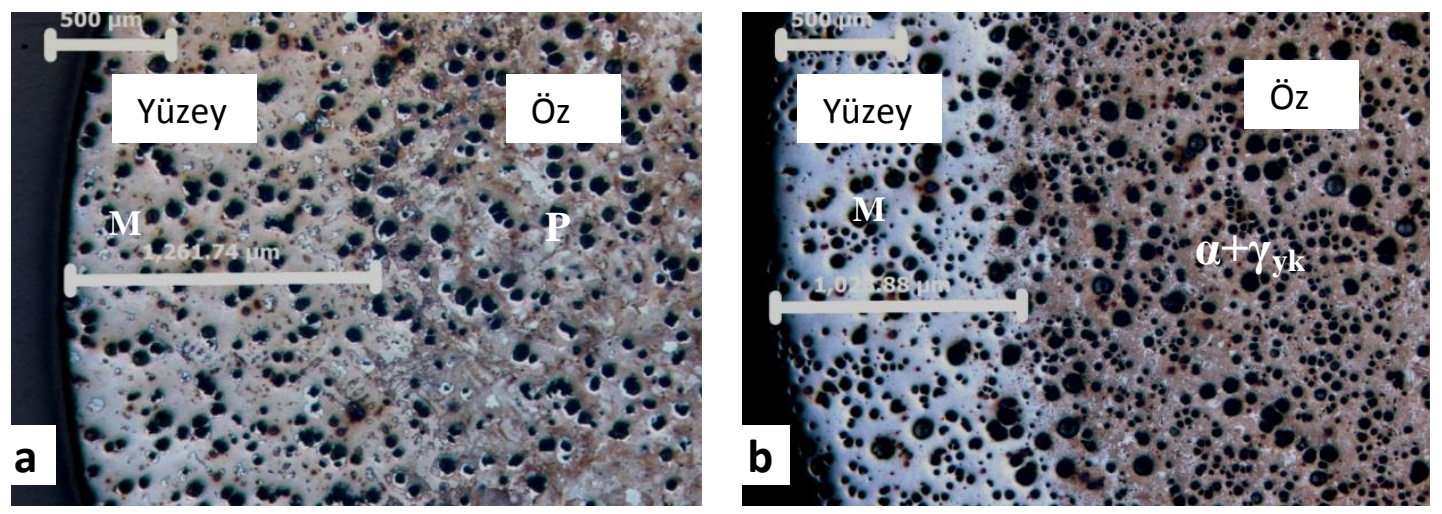

Şekil 4. a) Indüksiyonla yüzeyi sertleştirilmiş KGDD’nin mikroyapısı, b) Indüksiyonla yüzeyi sertleştirilmiş östemperlenmiş KGDD'in mikroyapısı, P: Perlit, M: Martensit, $\alpha+\gamma_{v k}$ : Ösferrit, Dağlama: $\% 2$ Nital. (Figure 4. a) Microstructure of induction surface hardened as-cast ductile iron, b) Microstructure of induction surface hardened austempered ductile iron, P: Pearlite, M: Martensite, $\alpha+\gamma_{y k}$ : Ausferrit, Etchant: 2\% Nital)

Şekil 4.b'de İYS+ÖKGDD numunesinin mikroyapısı görülmektedir. Sertleştirme işlemi sonucunda yüzeyden 1,02 mm'lik derinliğe kadar martensitik yapı elde edilmiştir. Yüzeyden uzaklaştıkça martensitik bölgeden ösferritik mikroyapıya geçiş görülmektedir. Numunenin merkez bölgesi ise tamamen ösferritik yap1 olup İYS işleminin herhangi bir etkisi gözlenmemektedir. Böylece numunenin yüzeyi sert martensitik yapı, özü ise sünek ösferritik mikroyapıya sahip olmuştur.

\subsection{Mekanik Özellikler (3.2. Mechanical Properties)}

\subsubsection{Sertlik profili (3.2.1. Hardness Profile)}

IYYS+KGDD ve İYS+ÖKGDD numunelerinin sertlik profilleri Şekil 5'te, yüzey sertlik değerleri ise Tablo 3 'te verilmiştir. Etkin sert katman derinliği yaklaşık 0,93-1,37 mm civarında gerçekleşmiştir. Bu derinliği daha da artırmak mümkün olmakla beraber standart yorulma numunesinin en dar kesit çap1 (8mm) dikkate alındığında daha fazla sert katman derinliği özellikle bu kesit alandaki ösferritik yapının miktarını azaltması söz konusu olduğundan ortalama etkin sertlik derinliği olarak 1,15 mm'lik sert katman derinliğine karar verilmiştir. Yüzeyi sertleştirilen östemperlenmiş numunenin yüzeyden öze oluşturulan iz görüntüleri Şekil 6'da verilmiştir. Martensitik yapının oluştuğu sert yüzeyde iz alanı küçük yumuşak ösferritik yapının uluştuğu özde ise büyük görünmektedir. 


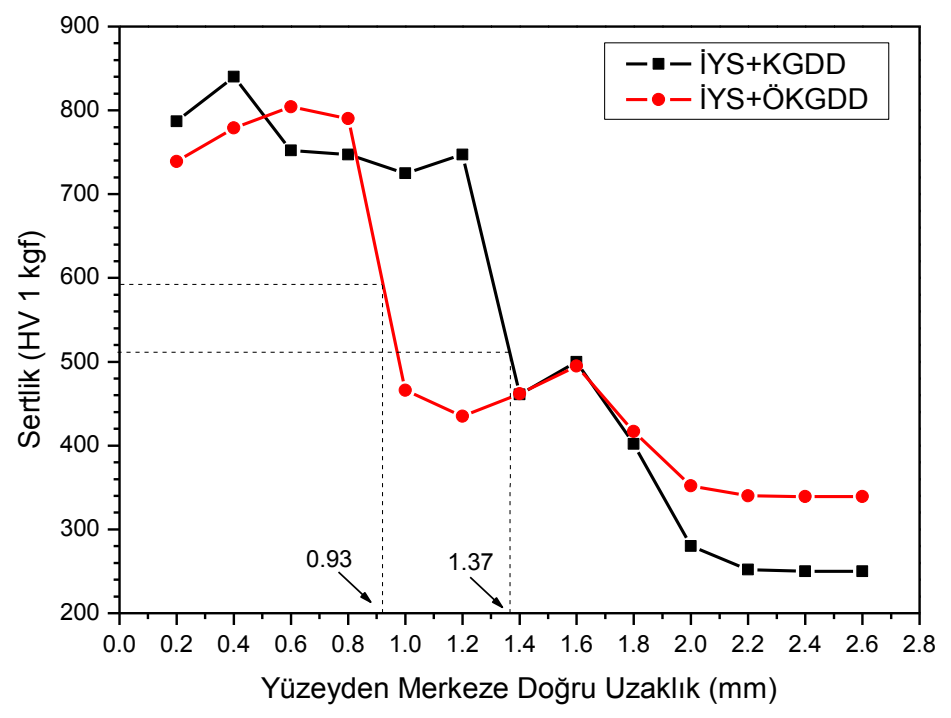

Şekil 5. Indüksiyonla yüzeyi sertleştirilmiş numunelerin sertlik profilleri; IYS + KGDD: İndüksiyonla yüzey sertleştirilmiş küresel grafitli dökme demir, IYS+ÖKGDD: Indüksiyonla yüzey sertleştirilmiş östemperlenmiş küresel grafitli dökme demir (Figure 4. Hardness profiles of induction surface hardened samples; IYS + KGDD: Induction surface hardened ductile iron, IYS+ÖKGDD: Induction surface hardened austempered ductile iron )

Tablo 3. Numunelerin yüzey ve öz bölgesi sertlik değerleri (Tablo 3. Surface and core hardness values of samples)

\begin{tabular}{|l|c|c|}
\hline Numune Kodu & Yüzey Sertliği (HV 30 kgf) & Öz Sertliği (HV 30 kgf) \\
\hline KGDD & $247 \pm 5.8$ & $251 \pm 10.9$ \\
\hline İYS + KGDD & $639 \pm 20.9$ & $250 \pm 7$ \\
\hline ÖKGDD & $339 \pm 15.3$ & $328 \pm 7.6$ \\
\hline İYS + ÖKGDD & $740 \pm 40.1$ & $415 \pm 6.4$ \\
\hline
\end{tabular}

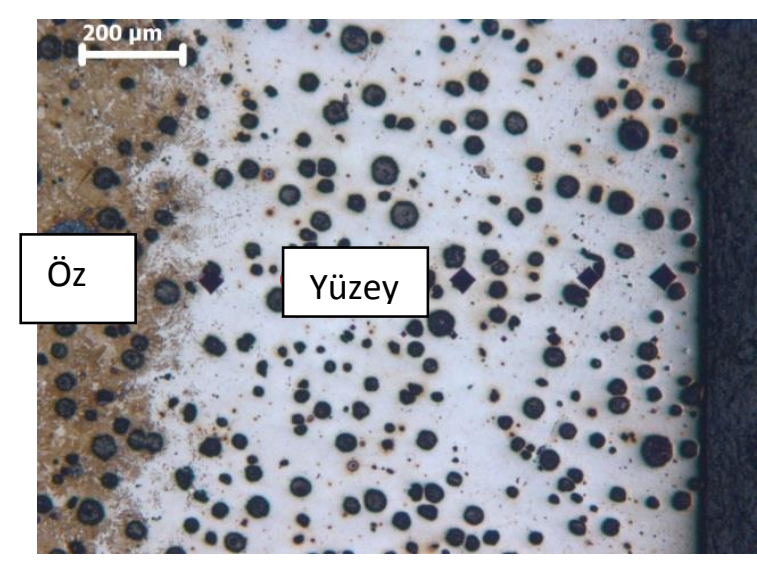

Şekil 6. Yüzeyi sertleştirilen östemperlenmiş numunedeki sertlik izleri (Figure 5. Hardness indentations in induction surface hardened austempered ductile iron)

\subsubsection{Yorulma özellikleri (3.2.2. Fatigue properties)}

Bütün numunelerinin yorulma snırlarınıa gösteren S-N eğrileri Şekil 7'de verilmiştir. Deneysel sonuçlar, numunelerin yorulma sınırı mikroyapıdaki değişimleri yansıttığını ortaya koymuştur. Ferrit + perlitik 
mikroyapıya sahip KGDD numunesi diğer test edilen numunelere kıyasla en düşük yorulma sınırı sergilemiştir (Şekil 7). Bu numunedeki daha düşük yorulma sınırı ferritin sünek doğasına atfedilebilir. Mikro çatlak tumuşak ve sünek ferritik yapıda daha kolay ve hızlı yayılmaktadır [26].

Yüksek karbonlu östenit + beynitik ferrite sahip ÖKGDD numunesinde KGDD numunesinden daha yüksek yorulma sınırı elde edilmiştir. Bu sonuç literatürle paralellik göstermektedir [2, 10, 27-34]. Östemperleme ile yorulma sınırındaki bu artış, ince ösferritik yapının perlitik yapıya göre yorulma çatlaklarının ilerlemesine karşı direncini artırdığına dayandırılmaktadır[10, 27-36].

Çatlak ilerlemesine karşı direnç ve yorulma sınırı ösferrit yapının miktarına, yapıdaki homojen dağılımına ve inceliğine bağımlıdır. Ösferritin ince olması tane sınırlarının artmasına böylece yorulma sınırının artmasında etkili olmaktadır [36]. Artan tane sınırları iç gerilmelerin hareketini engelleyerek bu gerilmelerin birleşmesini geciktirerek çatlak oluşumunu yavaşlatmaktadır[37].

İYS+KGDD ve İYS+ÖKGDD numunelerinin yorulma sınırlarında KGDD ve ÖKGDD numunelerine yorulma sınırlarına göre önemli bir artış gözlenmiştir (Tablo 4). Bu artışın nedeni yüzeydeki oluşturulan martensitik yapıya dayandırılmaktadır [14]. Östenitten martensite dönüşüm hacimce büyümeyi gerektirdiği için yüzeyi sertleştirilen katmandaki genleşme basma kalıntı gerilmeleri oluşturmaktadır. Basma kalıntı gerilmeleri yorulma çatlaklarının başlatılmasına ve yayılmasına karşı direncin artmasına katkıda bulunmaktadır. Bu sonuçlar, ana yorulma çatlaması yayılım davranışının, martensit tarafından üretilen basma kalıntı gerilme alanından kuvvetle etkilendiğini vurgulamaktadır.

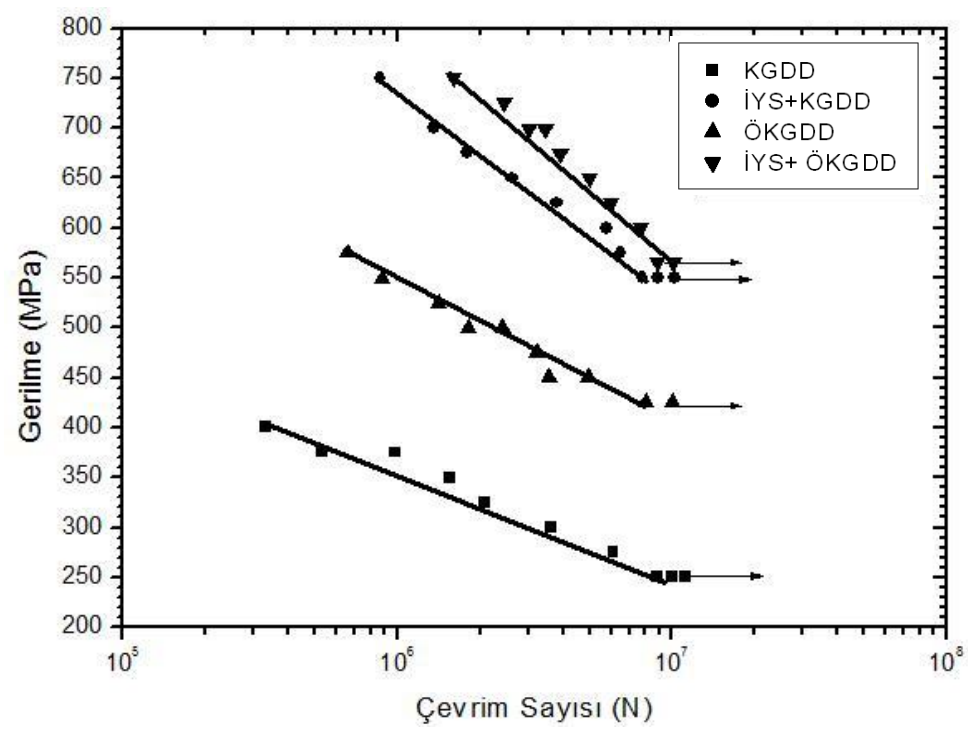

Şekil 7. Numunelerin tamamına ait $S-N$ eğrileri (Figure 6. $S-N$ curves of all samples)

Tablo 4. Numunelerin yorulma sinırı değerleri (Table 4. Fatigue limit values of samples)

\begin{tabular}{|l|c|}
\hline \multicolumn{1}{|c|}{ Numune Kodu } & Yorulma sinırı (MPa) \\
\hline KGDD & 250 \\
\hline İYS + KGDD & 550 \\
\hline ÖKGDD & 450 \\
\hline İYS + ÖKGDD & 565 \\
\hline
\end{tabular}

\subsection{Yorulma Numunelerinin Kırık Yüzey İncelemesi (3.3. Examination of Fracture Surfaces of Fatugue Samples)}

KGDD numunesinin girintili çıkıntılı ve çukurcuklar içeren kırık yüzey SEM görüntüleri kırılma modunun sünek tip olduğunun göstermektedir (Şekil 8). Grafit, genel olarak bir çatlama başlatma alanının bir kaynağıdır, çünkü kırılgan ve düşük mukavemetli grafit, dökme demirde bir iç çatlak görevi 
görmektedir [26]. Grafit çatlak başlatma için bir kaynaktır. Burada çatlak başlangıç noktası grafitin çevresinde konumlandığını ve çatlağın grafit boyunca yayıldığı ve grafit nodüllerinin bağlandığ1 görülmektedir (Şekil 8.b). Yorulma çatlağı, nodüller arasındaki matriste en az direnç yolunu izlemektedir.

Çatlak oluşumu ve ilerleyişi grafitlerin etrafinda gerçekleştiği için bu davranış çatlağın malzemenin diğer bölgelerine ilerleyişini yavaşlatarak yorulma sınırını artırmaktadır.

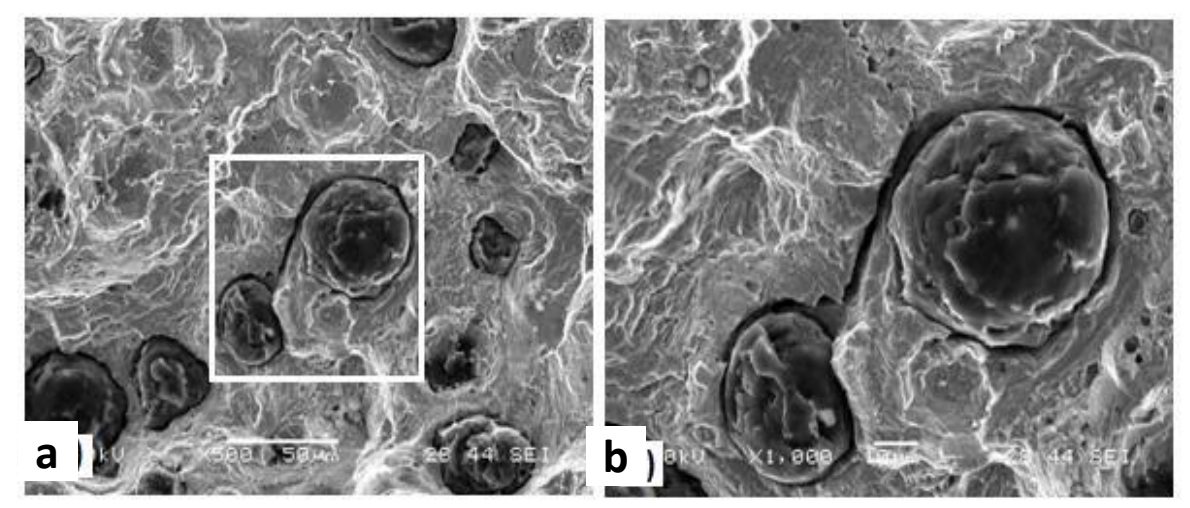

Şekil 8. Dökülmüs koşullardaki küresel grafitli dökme demir numunenin (KGDD) kırlk yüzey SEM görüntüleri;a) Büyütme: X500, b)Büyütme: X1000. (Figure 8. SEM fractography of ductile iron sample in as cast condition; a) Magnification: X1000, b) Magnification: X500).

ÖKGDD kısmen çukurcuklu (dimples) sünek kısmen de düzgün yüzey ayrılmalı gevrek kırılma modu sergilemiştir (Şekil 9). Östemperleme işlemi ile elde edilen ince ösferrit yapının sertliği artırması kırık yüzeylerin daha düzgün ve küçük çukurcuklar şeklinde kırılmasını sağlamış olabilir. Şekil 9.a'da görülebileceği gibi bazı çatlak oluşumları döküm hatalarından kaynaklanabilir. Bir miktar grafit-matris arayüzlerinde ayrışmalar ve yoğun çatlak dallanma davranışı (Şekil 9.a ve b) önceki çalışmaların sonuçlarını desteklemektedir [2,38]. Grafit-matris arayüzleri arasındaki ayrışma oluşumu, grafitin ve matris yapısının mekanik özelliklerinde uyumsuzluğa bağlanmaktadır. Lin ve ark. ayrışmanın ADI'nın düşük gerinim düzeyinde grafit-matris arayüzlerinde gerçekleştiğini bildirmişlerdir [38].
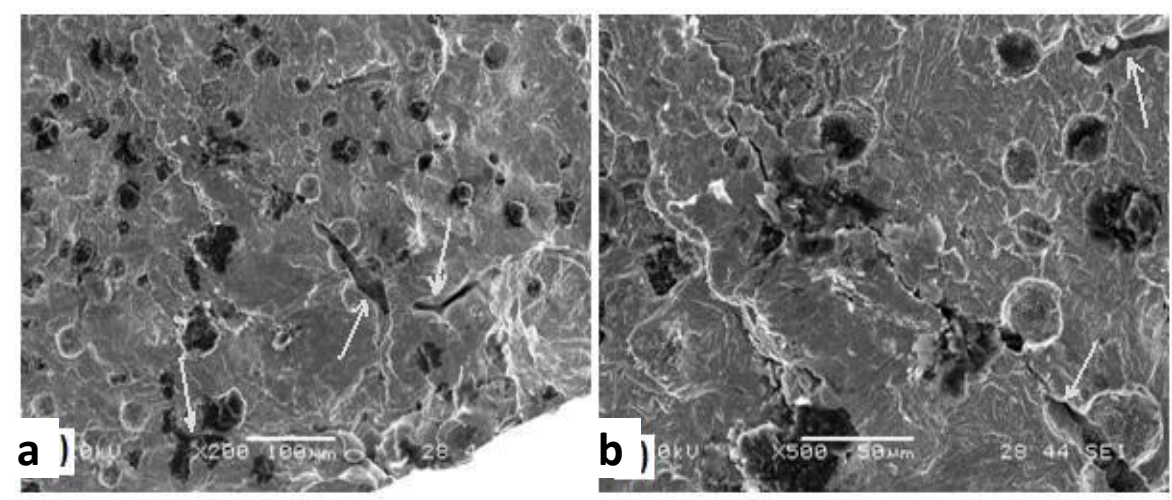

Şekil 9. Östemperlenmiş küresel grafitli dökme demir nunumenin (ÖKGDD) ktrı yüzey SEM görüntüleri; a) Büyütme: X200, b) Büyütme: X500. (Figure 9. SEM fractography of austempered ductile iron sample; a) Magnification: X200, b) Magnification: X500).

IYYS+KGDD numunelerinin yorulma testi sonucunda oluşan kırık yüzeylerin iki farklı kırılma yüzeyine sahip olduğu görülmektedir (Şekil 10). İndüksiyonla yüzey sertleştirme sonucu yüzeyden 1,2 mm'lik derinliğe kadar oluşturulan martensitik tabakadan dolayı bu bölgede yüzey düzgün yüzey ayrılma 
(clevage) şekilde meydana gelirken öze doğru gidildikçe martensit tabakanın etkisi azalmış ve buna paralel olarakta kırılma sünek olduğunu gösteren çukurcuklar (dimples) oluştuğu gözlenmiştir (Şekil 10.a). Bu sonuç literatürle aynı doğrultudadır $[14,16]$.

Şekil 10.c ve Şekil 10.d'de görüleceği üzere çatlaklar tane sınırlarında hareket ederek grafite dayandığ görülmektedir. Grafit çatlağın ilerleme hızını yavaşlatarak yorulma sınırını artırmaktadır [14].
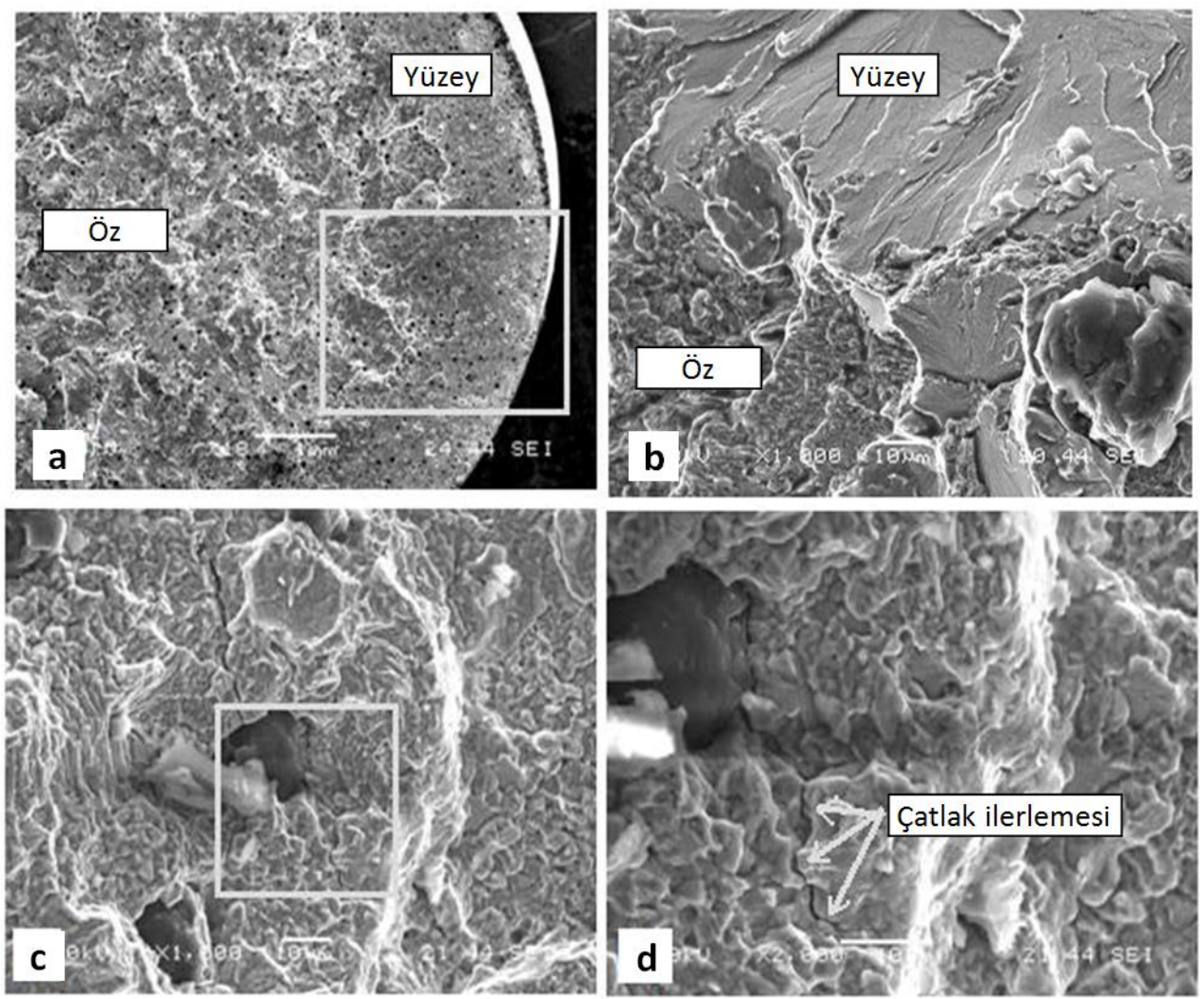

Şekil 10. Dökülmüş ve indüksiyonla yüzeyi sertleştirilmiş numunenin (IYS+KGDD) kirı yüzey SEM görüntüleri;a) Büyütme: X18, b)Büyütme: X1000, c)Büyütme: X1000, b)Büyütme: X2000. (Figure 10. SEM fractography of surface hardened as cast ductile iron sample; a) Magnification: X18, b) Magnification: X1000, c) Magnification: X1000, d) Magnification: X2000).

IYYS+ÖKGDD numunelerinde yüzeyden öze doğru kırılma modunun gevrekten süneğe doğru değiștiği gözlenmiştir (Şekil 11.a). Bu sonuç östemperleme işlemi ile özde oluşturulan ösferrit yapıya ve İYS işlemi ile yüzeyde oluşturulan martensit yapıya dayandırılabilir. Böylece numunenin yüzeyinde gevrek kırılma, içinde ise sünek kırılma meydana geldiğini göstermektedir. Ayrıca yüzeydeki parçacıkların kopması da gevrek kırılma olduğunu göstermektedir (Şekil 11.a). 

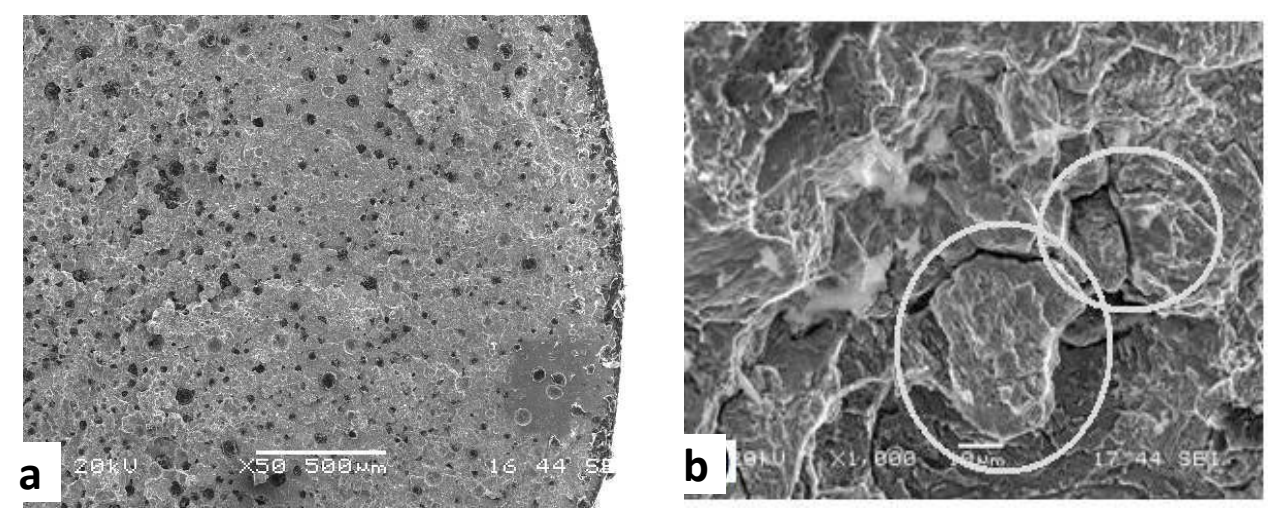

Şekil 11. Indüksiyonla yüzeyi sertleştirilmiş östemperlenmiş küresel grafitli dökme demir nunumenin (IYS+ÖKGDD) kırı yüzey SEM görüntüleri; a) Büyütme: X500, b)Büyütme: X1000. (Figure 11. SEM fractography of induction surface hardened austempered ductile iron; a) Magnification: X500, b) Magnification: X1000).

\section{SONUÇLAR (4. CONCLUSIONS)}

İndüksiyonla yüzey sertleştirme işleminin, küresel grafitli dökme demirlerin ve östemperlenmiş küresel grafitli dökme demirlerin mikroyapı ve yorulma özelliklerinin araştırıldığı bu çalışmada aşağıdaki sonuçlar elde edilmiştir;

1. Dökülmüş ve östemperlenmiş koşullardaki indüksiyonla yüzeyleri serleştirilen numunelerin yorulma sınırları, dökülmüş ve östemperlenmiş koşullardaki numunelerin yorulma sınırlarına göre yaklaşık iki katından fazla gerçekleşmiştir.

2. Test edilen numuneler arasında en iyi yorulma sınırı sonuçlarını östemperlenmiş+yüzeyi indüksiyonla sertleştirilmiş numuneler sergilemiştir.

3. Dökülmüş koşullardaki numunenin kırılma yüzeyleri çukurcuklu (dimples) sünek kırılma modu sergilemiş̧ir. Östemperlenmiş numunelerde ise kısmen gevrek (quasi-cleavage) kısmen de çukurcuklu (dimples) sünek kırılma davranışı gözlenmiştir.

4. Dökülmüş ve östemperlenmiş koşullardaki indüksiyonla yüzeyleri serleştirilen numunelerin sertleştirilen martensitik yapıya sahip kısımlarında düzgün yüzey ayrılmalı gevrek kırılma modu gözlenirken özde ise çukurcuklu (dimples) sünek kırılma modu gözlenmiştir.

\section{TEŞEKKÜR (ACKNOWLEDGEMENTS)}

$\mathrm{Bu}$ çalışmayı destekleyen Gazi Üniversitesi Bilimsel Araştırma Projelerine (GÜBAP 07-2010-32) teşekkür ederiz. Ayrıca indüksiyonla yüzey sertleştirme işlemi için Termo İndüksiyon Isıl İşlem ve Makine Sanayi Ticaret Ltd. Şti.’ye teşekkür ederiz.

\section{KAYNAKLAR}

[1] Nofal, A., Jekova, L. Novel processing techniques and applications of austempered ductile iron. J.Univ. of Chem. Tech. and Metall., 44(213-228), (2009).

[2] Bartosiewicz, L., Krause, A., Alberts, F., Singh, I., Putatunda, S.K. Influence of microstructure on high-cycle fatigue behavior of austempered ductile cast iron. Mater. Charac., 30(221-234), (1993).

[3] Bartosiewicz, L., Krause, A., Kovacs, B., Putatunda, S.K. Fatigue Crack Growth, Behaviour of Austempered Ductile Cast Iron. AFS Trans., 92(135-142), (1992).

[4] Dodd, J. High strength, high ductility, ductile irons. Modern Casting, 68(60-66), (1978).

[5] Gundlach, R.B., Janowak, J.F. Austempered ductile iron combines strength with toughness and ductility. Metal Progress, 128(19-26), (1985). 
[6] Harding, R. Why the properties of austempered ductile irons should interest engineers. British Foundryman, 79(489-496), (1986).

[7] Johansson, M. Austenitic-bainitic ductile iron. AFS Trans., 85((1977).

[8] Putatunda, S.K. Development of austempered ductile cast iron (ADI) with simultaneous high yield strength and fracture toughness by a novel two-step austempering process. Materi. Sci. and Eng. A, 315(70-80), (2001).

[9] Schmidt, I., Schuchert, A. Unlubricated sliding wear of austempered ductile iron. Z. Metallkd., 78(871-875), (1987).

[10] Shanmugam, P., Rao, P.P., Udupa, K.R., Venkataraman, N. Effect of microstructure on the fatigue strength of an austempered ductile iron. J. Mater. Sci., 29(4933-4940), (1994).

[11] Keough, J., Hayrynen, K., Pioszak, G. Designing with austempered ductile iron (ADI). AFS Trans., 118(1-15), (2010).

[12] Kovacs, B. Development of austempered ductile iron (ADI) for automobile crankshafts. Journal of Heat Treating, 5(55-60), (1987).

[13] Druschitz, A.P., Thelen, S. Induction hardened ductile iron camshafts. SAE 2002 World Congress \& Exhibition, (2002).

[14] Kim, J.-D., Ji, J.-K. Effect of super-rapid induction quenching on fatigue fracture behavior of spherical graphite cast iron FCD500. J. Mater. Proc. Tech., 176(19-23), (2006).

[15] Ma, H. (2012). The Quantitative Assessment of Retained Austenite in Induction Hardened Ductile Iron, University of Winsdor,

[16] Misaka, Y., Kawasaki, K., Komotori, J., Shimizu, M. Fatigue strength of ferritic ductile cast iron hardened by super rapid induction heating and quenching. Mater. Trans., 45(2930-2935), (2004).

[17] Nateq, M.H., Kahrobaee, S., Kashefi Torbati, M. Nondestructive characterization of induction hardened cast iron parts. 2nd International Conference on Materials Heat Treatment, (2011).

[18] Rudnev, V.I. Induction Hardening Cast Iron. Heat Treating Progress, 3(27-32), (2003).

[19] Smoljan, B., Cajner, F., Landek, D. An analysis of induction hardening of ferritic ductile iron. $J$. Mater. Eng. Perform., 11(278-282), (2002).

[20] Mahmoud, A., Mohamed, M. Laser Surface Hardening of Ductile Cast Iron. Machines, Technologies, Materials, 12(3-6), (2013).

[21] Roy, A., Manna, I. Mathematical modeling of localized melting around graphite nodules during laser surface hardening of austempered ductile iron. Optics and Lasers in Eng., 34(369-383), (2000).

[22] Roy, A., Manna, I. Laser surface engineering to improve wear resistance of austempered ductile iron. Materi. Sci. and Eng. A, 297(85-93), (2001).

[23] Sohi, M.H., Karshenas, G., Boutorabi, S. Electron beam surface melting of as cast and austempered ductile irons. J. Mater. Proc. Tech., 153(199-202), (2004).

[24] Soriano, C., Leunda, J., Lambarri, J., Navas, V.G., Sanz, C. Effect of laser surface hardening on the microstructure, hardness and residual stresses of austempered ductile iron grades. Applied Surf. Sci., 257(7101-7106), (2011).

[25] Suh, D., Lee, S., Koo, Y., Kwon, S.-J. Surface hardening of a ductile-cast iron roll using high-energy electron beams. Metall. Mater. Trans. A, 28(1499-1508), (1997).

[26] Wade, N., Ueda, Y. Continuous Heating Transformation of Spheroidal Graphite Cast Iron. Trans. Iron Steel Inst. Jpn., 20(857-861), (1980).

[27] Bahmani, M., Elliott, R., Varahram, N. The relationship between fatigue strength and microstructure in an austempered Cu-Ni-Mn-Mo alloyed ductile iron. Journal of Mater. Sci., 32(5383-5388), (1997).

[28] Greno, G., Pardo, E., Boeri, R. Fatigue of austempered ductile iron. AFS Trans., 106(31-37), (1998).

[29] Jahangiri, M., Ahmadabadi, M.N., Farhangi, H. Enhancement of fatigue properties of ductile irons by successive austempering heat treatment. J. Mater. Eng. Perform., 20(1642-1647), (2011).

[30] Luo, J., Bowen, P., Harding, R. Evaluation of the fatigue behavior of ductile irons with various matrix microstructures. Metall. Mater. Trans. A, 33(3719-3730), (2002).

[31] Salman, S., Findık, F., Topuz, P. Effects of various austempering temperatures on fatigue properties in ductile iron. Mater. \& Des., 28(2210-2214), (2007).

[32] Tayanc, M., Aztekin, K., Bayram, A. The effect of matrix structure on the fatigue behavior of austempered ductile iron. Mater. \& Des., 28(797-803), (2007).

[33] Toktaş, G., Toktaş, A., Tayanç, M. Influence of matrix structure on the fatigue properties of an alloyed ductile iron. Mater. \& Des., 29(1600-1608), (2008). 
[34] Yamanaka, M., Tamura, R., Inoue, K., Narita, Y. Bending fatigue strength of austempered ductile iron spur gears. Journal of Adv. Mech. Des. Sys. and Man., 3(203-211), (2009).

[35] Ovali, I., Kilicli, V., Erdogan, M. Effect of microstructure on fatigue strength of intercritically austenitized and austempered ductile irons with dual matrix structures. ISIJ Int., 53(375-381), (2013).

[36] Ovali, I. (2006). Kritik Tavlama Sicaklıklarından Östemperlenmiş Çift Matrisli Alaşımsız Küresel Grafitli Dökme Demirlerin Yorulma Özellikleri, Yüksek Lisans Tezi, Gazi Üniversitesi Fen Bilimleri Enstitüsü, Ankara, 31-32.

[37] Wohlfahrt, M., Oberwinkler, C., Tunzini, S., Rauscher, A., de la Prida Caballero, R., Eichlseder, W. The role of sampling position on fatigue of austempered ductile iron. Procedia Eng., 2(1337-1341), (2010).

[38] Lin, C.-K., Lai, P.-K., Shih, T.-S. Influence of microstructure on the fatigue properties of austempered ductile irons-I. High-cycle fatigue. Int. J. Fatigue, 18(297-307), (1996). 